\title{
Emoções em Estudos Organizacionais: Contribuições e desafios ao campo
}

\section{Emotions in Organizational Studies: Contributions and challenges to the field}

MARIANE LEMOS LOURENÇO

\section{RESUMO}

As emoções são um tema incipiente na área de estudos organizacionais e possibilitam inúmeras interpretações e pequisas a seu respeito. Assim, considerando-se a novidade da temática ao campo, a partir da técnica metassíntese foi possível formular o seguinte questionamento norteador deste artigo: Como as emoções são abordadas na área de estudos organizacionais? Os principais resultados demonstraram que as emoções em estudos organizacioanis são vistas como aspectos emergentes influenciados pelo contexto e, em estudos de caso, raramente são o foco principal. Com este estudo, constata-se outras maneiras de se trazer as emoções para estudos organizacionais que possuem o potencial de desenvolvimento e discussão. Expõe-se, por fim, maneiras de se aprofundar a referida temática, provendo direções para futuras pesquisas com base nos achados dos artigos selecionados. Palavras-chave: Emoções; metassíntese; estudo de caso; estudos organizacionais.

\section{Abstract}

Emotions are an incipient theme in the area of organizational studies and allow numerous interpretations and researches in their respect. Thus, considering the novelty of the theme to the field, based on the metasynthesis technique, it was possible to formulate the following guiding question of this article: How are 
emotions approached in the area of organizational studies? The main results showed that emotions in organizational studies are seen as emerging aspects influenced by the context and, in case studies, are rarely the main focus. With this study, other ways of bringing emotions into organizational studies that have the potential for development and discussion are found. Finally, ways to deepen this theme, providing directions for future research based on the findings of selected articles are exposed.

Keywords: Emotions; metasynthesis; case study; organizational studies.

\section{INTRODUÇÃo}

As emoções sempre fizeram parte da atividade humana, todavia, sua influência na atividade organizacional foi negligenciada por muito tempo. Nos últimos anos, porém, esse cenário está se modificando a ponto de serem encontradas interessantes possibilidades de estudo das emoções no interior das organizações, bem como as decorrências de sua existência (FINEMAN, 2001).

A abordagem da emoção em estudos organizacionais é recente (ASHKANASY, 2003; BRAMMING; JOHNSEN, 2011; GOOTY et al., 2010; BARRETT; LEWIS; HAVILAND-JONES, 2016), assim como a própria utilização do termo nessa área (JOST; BULGACOV; CAMARGO, 2018). Com o objetivo de melhor compreender a forma como essa temática tem sido explorada em pesquisas da área de estudos organizacionais, passa-se a identificar, neste artigo, os trabalhos que já a tenham discutido.

Para tanto, utilizou-se a técnica da metassíntese proposta por Hoon (2013) que, por ser um projeto de pesquisa exploratória e indutiva, permite ao pesquisador sintetizar pesquisas após a busca e análise de estudos de casos qualitativos que tragam contribuições ao assunto pesquisado e, também, que tragam evidências para o desenvolvimento de contribuições além das já alcançadas nos estudos originais.

Assim, conforme proposto por Hoon (2013), o presente estudo segue os oito passos constituintes do protocolo de metassíntese da autora, partindo da elaboração de uma pergunta de pesquisa específica que norteie os demais aspectos e que, por fim, apresente 
uma discussão que demonstre as relações encontradas nos estudos selecionados.

Com base em estudos de caso qualitativos selecionados em bases de dados nacionais e internacionais, procurou-se então responder o seguinte questionamento: Como as emoções são abordadas na área de estudos organizacionais?

\section{EMOÇõES EM ESTUDOS ORGANIZACIONAIS}

Os estudos organizacionais podem ser conceituados como uma série de conversações desenvolvidas por pesquisadores que, em decorrência, permitem constituir as organizações por meio de termos que derivam de paradigmas, métodos e suposições (CLEGG; HARDY, 1999). Trata-se, então, de uma área de pesquisa a respeito de organizações e suas características, sejam essas culturais, econômicas, políticas ou sociais, bem como dos efeitos que as organizações possam dispor sobre os indivíduos e grupos que as compõem ou com as quais interagem (THIOLLENT, 2014).

Diante de tal contexto, cabe destacar que o interesse em estudar emoções em estudos organizacionais desenvolveu-se, especificamente, nas últimas décadas quando a sua relevância e influência foram reconhecidas não somente para as vidas pessoais dos indivíduos, mas, também, em questões relacionadas à carreira profissional (LIVELY; WEED, 2014). Embora, porém, o estudo das emoções em ambientes de trabalho não seja algo novo, a pesquisa empírica no campo das ciências organizacionais ainda é um tanto quanto lenta (ASHKANASY, 2003). Com um pensamento semelhante quanto à relevância das emoções em tal área, Hochschild (1990) ressaltou que as emoções são importantes para assuntos sociais, mas, também, que se destacam ao colocarem em pauta pensamentos e ações.

As emoções podem ser consideradas uma espécie de "guarda-chuva" por conta de compreenderem um grande escopo de sentimentos que os indivíduos costumam experimentar em momentos específicos de suas vidas (BARSADE; GIBSON, 2007, BRODY; HALL; STOKES, 2016). Ao estudá-las, o pesquisador pode abordá-las de forma geral ou, também, ter por foco uma única emoção como, por exemplo, amor (BRAMMING; JOHNSEN, 2011), paixão (POLLACK et al., 2020), vergonha (PLATE, 2015), medo (CAMAR- 
GO; LOURENÇO; FERREIRA, 2018), empatia (BURCH et al., 2016), entre outras.

É importante ressaltar, também, que cada tipo de emoção possui alguma influência, seja interpessoal, situacional, motivacional, cognitiva ou voltada a questões culturais (BRODY; HALL; STOKES, 2016). Apesar de haver consciência quanto à sua importância, na área de estudos organizacionais o uso do termo "emoções" ainda é recente (JOST; BULGACOV; CAMARGO, 2018), assim como os próprios estudos a respeito da temática (ASHKANASY, 2003). Percebe-se, no entanto, que para os pesquisadores da área, as dimensões emocionais permeiam todo o espectro do comportamento e da interação humana, incluindo as organizações (ASHKANASY, 2003).

É relevante ressaltar, contudo, que as emoções possuem grande influência dentro de um ambiente organizacional por se relacionarem com processos e resultados organizacionais, tais como performance, processo de tomada de decisão, criatividade, comportamento social, trabalho em equipe, negociação e liderança (FINEMAN, 2001; BARSADE; GIBSON, 2007) e, que integram expressões pessoais do trabalho, consequentemente, da vida organizacional (FINEMAN, 2001).

A emoção está vinculada aos significados e necessidades de um indivíduo conforme este traça a sua trajetória, todavia, os recursos subjetivos que a abrangem são fruto de estados afetivos disponíveis no desenvolvimento de cada atividade (GONZÁLEZ REY, 2003). Nesse sentido, destaca-se o estudo de Jost, Bulgacov e Camargo (2018) para quem a emoção pode ser aprendida por meio da dimensão subjetiva da ação do sujeito, expressando-se concretamente nos processos sociais e nas relações que o indivíduo constitui em nível pessoal e grupal, bem como por meio de aspectos históricos e culturais.

Por conta disso, é relevante destacar, também, que conforme o gênero do indivíduo existem diferenças nas emoções expressas justamente por consequência de variáveis voltadas à personalidade, além de aspectos sociais, culturais e situacionais que, por sua vez, acabam interferindo na qualidade e características das emoções experimentadas (BRODY; HALL; STOKES, 2016).

De acordo com o exposto por Erickson e Ritter (2011), homens e mulheres possuem diferentes experiências emocionais. As mulheres possuem tendência de exibirem emoções positivas (como, por 
exemplo, calma, felicidade e simpatia) e suprimir emoções negativas (como raiva), enquanto os homens tendem a exibir qualquer tipo de emoção, porém, não demonstram preocupação em exporem emoções negativas.

Observa-se, portanto, que há uma possível relação entre as emoções e os estudos organizacionais, tendo em vista que as emoções em contextos organizacionais, conforme destacado por Ahskanasy (2003), podem ser vistas por completo desde o nível individual até o organizacional. Não obstante, por se tratar de uma temática provinda da área da Psicologia (BRAMMING; JOHNSEN, 2011; GOOTY et al., 2010), o aprofundamento das emoções sob o ponto de vista dos estudos organizacionais ainda requer desenvolvimento. Ressalta-se que o conceito de emoções utilizado neste estudo é o desenvolvido por Barsade e Gibson (2007), e por conta de sua duração, elas se encontram envolvidas em processos afetivos, diferindo-se de humores.

\section{Procedimentos metodológicos}

Com a finalidade de compreender a forma como as emoções são abordadas em estudos organizacionais, utilizou-se o protocolo de metassíntese proposto por Hoon (2013, p. 523), que assim a define: "projeto de pesquisa exploratória e indutiva para sintetizar estudos de caso qualitativos primários com o objetivo de fazer contribuições além daquelas alcançadas nos estudos originais".

O método já foi utilizado em estudos da área da Administração, como é o caso de Justen et al. (2020), os quais estão voltados à inovação e desenvolvimento social; de Cruzara et al. (2020), que utilizaram a metassíntese para estudar o impacto da transformação digital e da indústria 4.0 sobre aspectos de valor; e de Seefeld e Ceni (2020), que visaram responder ao questionamento sobre o lugar das narrativas na mudança organizacional, o que indica que o método pode ser utilizado em diferentes perspectivas na área.

Destaca-se, assim, que o presente estudo possui abordagem qualitativa por conta desse tipo de pesquisa que visa entender, descrever e explicar os fenômenos sociais de diversas maneiras (FLICK, 2009; VIEIRA; RIVERA, 2012). A busca por estudos de caso deu-se devido ao método possibilitar entendimentos aprofundados sobre 
os fenômenos a serem estudados, considerando as suas particularidades (EISENHARDT, 1989; YIN, 2015).

Os termos utilizados na busca pelos estudos foram "emotion*" AND "organization* studies" AND “case stud". Cabe salientar que este último descritor foi inserido com a finalidade de garantir que os trabalhos selecionados tratassem de estudos de casos como previsto nos procedimentos de metassíntese detalhada por Hoon (2013).

Optou-se, então, pela seleção de artigos completos publicados em periódicos, excluindo os de revisão, dentre outros tipos, e considerando todos os anos disponíveis. Inicialmente, obteve-se a quantidade de 12 artigos: Web of Science (dois artigos); Scopus (um artigo); Sage (oito artigos) e Science Direct (um artigo). As bases Scielo e Spell não retornaram resultados com as respectivas traduções e combinações dos termos mencionados, enquanto os artigos retirados da plataforma Sage foram filtrados por periódicos de estudos organizacionais, o que caracterizou, então, uma busca manual, conforme previsto por Hoon (2013). Após esta seleção, os estudos foram organizados em uma planilha eletrônica para verificação de trabalhos comuns às bases. $\mathrm{O}$ artigo encontrado na base Scopus foi o mesmo de um dos achados na base Web of Science. Dessa forma, o artigo repetido foi identificado e excluído, resultando em 11 artigos para posterior análise.

A metassíntese proposta por Hoon (2013) é composta por oito etapas e para a análise da seleção dos artigos mencionados procedeu-se o desenvolvimento sugerido pela autora, conforme apresentado no Quadro 1: 
Quadro 1: Protocolo da metassíntese

\begin{tabular}{|c|c|c|c|}
\hline Passos & $\begin{array}{l}\text { Objetivo ana- } \\
\text { lítico }\end{array}$ & $\begin{array}{c}\text { Estratégia/Proce- } \\
\text { dimento analítico } \\
\text { utilizado }\end{array}$ & $\begin{array}{l}\text { Resultado para gerar } \\
\text { contribuição teórica }\end{array}$ \\
\hline $\begin{array}{l}\text { 1. Enquadramento } \\
\text { da questão de } \\
\text { pesquisa }\end{array}$ & $\begin{array}{l}\text { Enquadrar a metas- } \\
\text { síntese no campo da } \\
\text { pesquisa sobre estu- } \\
\text { dos organizacionais } \\
\text { e emoções, de forma } \\
\text { que seja possível iden- } \\
\text { tificar uma questão de } \\
\text { pesquisa que aborde } \\
\text { a forma como estão se } \\
\text { desenrolando as pes- } \\
\text { quisas de tal temática } \\
\text { na área mencionada. }\end{array}$ & $\begin{array}{l}\text { Buscas em bases de dados } \\
\text { científicas juntamente a } \\
\text { leituras a respeito do tema } \\
\text { "emoções na área de estudos } \\
\text { organizacionais". }\end{array}$ & $\begin{array}{l}\text { Identificação da lacuna } \\
\text { teórica a ser abordada na } \\
\text { metassíntese. }\end{array}$ \\
\hline $\begin{array}{l}\text { 2. Localização de } \\
\text { pesquisas rele- } \\
\text { vantes }\end{array}$ & $\begin{array}{l}\text { Identificar pesquisas } \\
\text { sobre emoções em } \\
\text { estudos organiza- } \\
\text { cionais que podem } \\
\text { ser consideradas } \\
\text { relevantes à questão } \\
\text { de pesquisa. }\end{array}$ & $\begin{array}{l}\text { Definição das palavras- } \\
\text { chave: "emotion*" AND } \\
\text { "organization* studies" AND } \\
\text { "case stud" aplicando-as } \\
\text { em buscas nas bases Web of } \\
\text { Science, Scopus, Science Direct, } \\
\text { Sage, Spell e Scielo. }\end{array}$ & $\begin{array}{l}\text { Considerando-se somente } \\
\text { artigos completos publicados } \\
\text { em periódicos, foram localiza- } \\
\text { dos dois artigos na base Web } \\
\text { of Science, dois na base Scopus, } \\
\text { um na base Science Direct e } \\
\text { oito na base Sage. }\end{array}$ \\
\hline $\begin{array}{l}\text { 3. Critérios de } \\
\text { inclusão }\end{array}$ & $\begin{array}{l}\text { Determinar os crité- } \\
\text { rios de inclusão dos } \\
\text { artigos que irão com- } \\
\text { por a metassíntese } \\
\text { e, automaticamente, } \\
\text { de exclusão daqueles } \\
\text { que não atendem ao } \\
\text { objetivo proposto. }\end{array}$ & $\begin{array}{l}\text { Leitura e seleção dos arti- } \\
\text { gos, selecionando os que se } \\
\text { enquadram nos critérios: } \\
\text { estudo de caso qualitativo, } \\
\text { que abranjam estudos orga- } \\
\text { nizacionais e que incluam } \\
\text { emoções em seu escopo. }\end{array}$ & $\begin{array}{l}\text { Dos } 12 \text { artigos encontrados, } \\
\text { quatro foram excluídos, tota- } \\
\text { lizando oito para a análise. }\end{array}$ \\
\hline $\begin{array}{l}\text { 4. Extração e codi- } \\
\text { ficação dos dados }\end{array}$ & $\begin{array}{l}\text { Proceder a leitura dos } \\
\text { artigos selecionados, } \\
\text { identificando carac- } \\
\text { terísticas relevantes } \\
\text { para o objetivo da } \\
\text { metassíntese. }\end{array}$ & $\begin{array}{l}\text { Elaboração de planilha } \\
\text { eletrônica, dividindo as } \\
\text { informações de cada artigo } \\
\text { em: título, autor(es), ano, } \\
\text { periódico, objetivo, emoção } \\
\text { utilizada, relação com estu- } \\
\text { dos organizacionais, estraté- } \\
\text { gia de pesquisa e principais } \\
\text { resultados relacionados às } \\
\text { emoç̃es. }\end{array}$ & $\begin{array}{l}\text { Visualização específica de cada } \\
\text { artigo com suas características } \\
\text { a fim de analisar as especifi- } \\
\text { cidades de cada publicação, } \\
\text { bem como obter uma visão do } \\
\text { conjunto. }\end{array}$ \\
\hline
\end{tabular}




\begin{tabular}{|c|c|c|c|}
\hline Passos & $\begin{array}{l}\text { Objetivo ana- } \\
\text { lítico }\end{array}$ & $\begin{array}{c}\text { Estratégia/Proce- } \\
\text { dimento analítico } \\
\text { utilizado }\end{array}$ & $\begin{array}{l}\text { Resultado para gerar } \\
\text { contribuição teórica }\end{array}$ \\
\hline $\begin{array}{l}\text { 5. Análise em nível } \\
\text { específico de cada } \\
\text { caso }\end{array}$ & $\begin{array}{l}\text { Identificar e analisar } \\
\text { a forma como as } \\
\text { emoções são aborda- } \\
\text { das em cada caso. }\end{array}$ & $\begin{array}{l}\text { Redes causais elaboradas } \\
\text { para cada caso analisado. }\end{array}$ & $\begin{array}{l}\text { Identificação dos principais } \\
\text { temas, o nível de análise } \\
\text { apresentado nos estudos e as } \\
\text { informações sobre o modo } \\
\text { como os casos exploram as } \\
\text { emoções. }\end{array}$ \\
\hline $\begin{array}{l}\text { 6. Síntese no nível } \\
\text { de estudo }\end{array}$ & $\begin{array}{l}\text { Chegar a um padrão } \\
\text { geral das variáveis, } \\
\text { mesclando as redes } \\
\text { causais de cada caso } \\
\text { em uma rede meta- } \\
\text {-causal, acumulando } \\
\text { o sequenciamento } \\
\text { de variáveis em } \\
\text { um nível de estudo } \\
\text { cruzado. }\end{array}$ & $\begin{array}{l}\text { Elaboração de redes causais } \\
\text { específicas de cada caso. }\end{array}$ & $\begin{array}{l}\text { Identificação de padrões } \\
\text { lógicos estabelecidos entre } \\
\text { os casos; identificação de } \\
\text { um padrão; processamento } \\
\text { cognitivo gerencial como } \\
\text { variável central; classificação } \\
\text { das variáveis para garantir a } \\
\text { validade. }\end{array}$ \\
\hline $\begin{array}{l}\text { 7. Criação da teoria } \\
\text { pela metassíntese }\end{array}$ & $\begin{array}{l}\text { Identificar a forma } \\
\text { como o tema "emo- } \\
\text { ções" é associado a } \\
\text { estudos organizacio- } \\
\text { nais em caso quali- } \\
\text { tativos. Demonstrar } \\
\text { uma contribuição } \\
\text { significativa para } \\
\text { os estudos do tema } \\
\text { na área de estudos } \\
\text { organizacionais. }\end{array}$ & $\begin{array}{l}\text { Associar os resultados à } \\
\text { literatura sobre "emoções". }\end{array}$ & $\begin{array}{l}\text { Identificar os conceitos e/ } \\
\text { ou tipos de emoções usados, } \\
\text { argumentando sobre as con- } \\
\text { tribuições à área de estudos } \\
\text { organizacionais. }\end{array}$ \\
\hline 8. Discussão & $\begin{array}{l}\text { Discutir os resulta- } \\
\text { dos da metassíntese, } \\
\text { bem como as limita- } \\
\text { ções da pesquisa. }\end{array}$ & $\begin{array}{l}\text { Discutir rigor, confiabilida- } \\
\text { de e validade. }\end{array}$ & $\begin{array}{l}\text { Legitimar a validade e con- } \\
\text { fiabilidade do procedimento } \\
\text { e das } \\
\text { atividades realizadas. }\end{array}$ \\
\hline
\end{tabular}

Fonte: adaptado de Hoon (2013).

Após definido o protocolo de metassíntese são apresentados os passos propostos por Hoon (2013) que possibilitam compreender a forma como as emoções são abordadas em pesquisas de casos sobre estudos organizacionais. 


\section{RESULTADOS}

Os resultados desta metassíntese foram organizados de acordo com os oito passos sugeridos por Hoon (2013).

\section{Passo 1: Enquadramento da questão de pesquisa}

O primeiro passo sugerido no estudo de Hoon (2013) está voltado à formulação da pergunta que permite o desenvolvimento de toda a pesquisa. De acordo com a autora, uma metassíntese tira proveito de uma pergunta de pesquisa bem especificada e teoricamente informada.

É importante, contudo, trazer algumas considerações que a justifique. Conforme destacado no estudo de Barsade e Gibson (2007) e, também, no de Brody, Hall e Stokes (2016), não existe uma definição exata acerca de emoções e, por essa razão, elas são definidas como "termos guarda-chuva", uma vez que abrangem ampla gama de sentimentos e podem estar relacionadas a processos afetivos. $\mathrm{Na}$ concepção dos autores, todavia, emoções diferem de humores por serem mais dinâmicas, e podem ser estudadas de maneira geral, sem que uma específica seja destacada ou, então, podem ter por foco uma única emoção, como descrito por Bramming e Johnsen (2011), Pollack et al. (2020), Plate (2015), Camargo, Lourenço e Ferreira (2018) e, também, por Burch et al. (2016).

Percebe-se, no entanto, que mesmo que pesquisadores saibam e destaquem a relevância das emoções no contexto organizacional, na área de estudos organizacionais os estudos sobre a temática ainda são recentes e carecem de mais desenvolvimento (ASHKANASY, 2003; JOST; BULGACOV; CAMARGO, 2018).

A fim de instigar mais estudos a respeito do tema e aprofundar a possibilidade de elaboração de um conceito para a área, o presente estudo é norteado pela seguinte questão: "como as emoções são abordadas na área de estudos organizacionais?"

\section{Passo 2: Localização de pesquisas relevantes}

Após definir a questão norteadora da pesquisa, buscou-se estudos que fossem relevantes para responder o questionamento, bem como que trouxessem contribuições importantes ao que propõe a metassíntese (HOON, 2013). As buscas por artigos foram realizadas 
nas bases de dados Web of Science, Scopus, Sage, Scielo, Science Direct e Spell. A seleção das bases foi realizada considerando os seus impactos de citação e em razão de se verificar em estudos anteriores a qualidade das pesquisas inseridas nas plataformas mencionadas.

Dessa maneira, em bases de dados internacionais utilizou-se o conjunto de palavras "emotion" AND "Organization* Stud" AND "case stud", em que o asterisco foi inserido com a finalidade de encontrar artigos que utilizassem variações dos termos. Em bases de dados nacionais utilizou-se a tradução dos termos "emoções" e "estudos organizacionais" e "estudos de caso", bem como o singular "emoção" e "estudo organizacional" e "estudo de caso". Outro ponto a salientar é que a plataforma Science Direct não comporta o uso de asterisco em suas buscas e, para evitar a perda de estudos relevantes, realizou-se duas buscas, ou seja, com os termos completos no singular e, posteriormente, no plural.

Todas as pesquisas foram realizadas durante a primeira semana do mês de julho de 2020. Salienta-se que a primeira base pesquisada foi a Web of Science, seguida das bases Scopus, Sage, Scielo e Spell, nessa ordem, sendo a Science Direct a última base pesquisada. Em todas as bases de dados optou-se pela busca de artigos completos publicados em periódicos, considerando a novidade do tema na área de Administração e, consequentemente, estudos organizacionais, sem restrição a um período de anos, considerando-se, assim, todos os anos disponíveis. Quanto aos campos selecionados procurou-se efetuar a busca naqueles que envolvessem "todos os resultados" ou relativos, tendo em vista as diferenças entre filtros de busca em todas as bases. Todos os artigos encontrados foram inseridos em uma planilha do programa Excel para melhor visualização, sendo os artigos repetidos excluídos para evitar a duplicação de dados. Os resultados são expostos no Quadro 2: 
Quadro 2: Periódicos, artigos e ano de publicação

\begin{tabular}{|l|c|c|}
\hline \multicolumn{1}{|c|}{ Periódico } & Quantidade & Ano \\
\hline Organization Studies & 2 & $2020 / 2018$ \\
\hline Business \& Society & 1 & 2019 \\
\hline International Journal of Cross-Cultural Management & 1 & 2019 \\
\hline Organizational Psychology Review & 1 & 2019 \\
\hline Acción psicológica & 1 & 2019 \\
\hline Frontiers in Psychology & 1 & 2018 \\
\hline Organization & 2 & $2016 / 2017$ \\
\hline SAGE Open & 1 & 2015 \\
\hline Industrial Marketing Management & 1 & 2013 \\
\hline \multicolumn{1}{|c|}{ Quantidade total: 11 artigos } & & \\
\hline
\end{tabular}

Fonte: A autoria (2021).

Por se tratar de estudos de caso que abordam emoções em seu escopo, verificou-se que os artigos resultantes da busca têm por contexto um melhor desenvolvimento desde 2013, ano do primeiro registro da pesquisa. Percebeu-se que estudos de caso que de alguma forma abordam as emoções em estudos organizacionais foram difundidos em 2019, ano que possui a maior quantidade de publicações que tratam da relação entre os dois aspectos selecionados. Aos artigos selecionados aplicou-se critérios de seleção a fim de que os resultados encontrados nessa metassíntese fossem mais efetivos.

\section{Passo 3: Critérios de inclusão e exclusão}

O terceiro passo refere-se aos critérios que auxiliem o pesquisador a filtrar os artigos finais a serem analisados de forma a trazer melhor compreensão e insights tanto para o estudo quanto para pesquisas futuras. Hoon (2013) destaca que sejam criados critérios de inclusão e consequente exclusão em virtude da necessidade de maior precisão na abordagem da metassíntese.

Pautando-se nas proposições da autora, realizou-se a leitura dos títulos, palavras-chave, resumos, introduções, objetivos, referenciais teóricos e principais resultados de todos os artigos selecionados nas bases de dados a fim de identificar estudos que atendessem 
aos critérios de inclusão apresentados no Quadro 3. Tais critérios, adaptados de Hoon (2013), estão voltados a três pontos principais: a abrangência de emoções nos artigos, o envolvimento com estudos organizacionais e a possibilidade de se tratarem de estudo de casos qualitativos.

Após a leitura, foram excluídos três artigos devido ao fato de não abordarem o tema "emoções" em seus escopos. Dessa maneira, a amostra final desta metassíntese foi composta por oito artigos. Apesar de ser considerada uma amostra pequena, Hoon (2013) destaca que a metassíntese tem por objetivo contribuir além dos resultados alcançados nos estudos originais, baseando-se na meta-análise dos estudos.

Considerando as proposições de Hoon (2013), apresentam-se no Quadro 3 os critérios de inclusão e os trabalhos excluídos:

\section{Quadro 3: Critérios de inclusão e trabalhos excluídos}

\begin{tabular}{|l|l|l|}
\hline \multicolumn{1}{|c|}{ Critério } & \multicolumn{1}{|c|}{ Descrição } & \multicolumn{1}{c|}{ Trabalhos excluídos } \\
\hline $\begin{array}{l}\text { Apenas estudos de casos quali- } \\
\text { tativos }\end{array}$ & $\begin{array}{l}\text { Artigos que consistam em estudos } \\
\text { de casos qualitativos, descritos na } \\
\text { metodologia ou que apresentem } \\
\text { tais características. }\end{array}$ & $\begin{array}{l}\text { Nenhum trabalho foi excluído por } \\
\text { esse critério. }\end{array}$ \\
\hline $\begin{array}{l}\text { Apenas artigos que incluam } \\
\text { "emoções" em seu escopo }\end{array}$ & $\begin{array}{l}\text { Artigos que abordem emoções, } \\
\text { seja em seus referenciais ou } \\
\text { como resultados emergentes. }\end{array}$ & $\begin{array}{l}\text { Becerra-Hernández, Menén- } \\
\text { dez-Fierros e Mapén-Franco } \\
\text { (2019) }\end{array}$ \\
Waring (2019) \\
\hline $\begin{array}{l}\text { Apenas artigos voltados a estu- } \\
\text { dos organizacionais }\end{array}$ & $\begin{array}{l}\text { Artigos voltados à área de estu- } \\
\text { dos organizacionais. }\end{array}$ & $\begin{array}{l}\text { Nenhum trabalho foi excluído por } \\
\text { esse critério. }\end{array}$ \\
\hline
\end{tabular}

Fonte: adaptado de Hoon (2013).

Considerando os critérios delineados no Quadro 3 e após a leitura dos artigos selecionados, no Quadro 4 detalha-se os artigos utilizados na análise, especificamente quanto aos seus autores, ano de publicação, títulos e periódicos: 


\section{Quadro 4: Informações sobre artigos selecionados para análise}

\begin{tabular}{|c|c|c|c|}
\hline Autor & Ano & Título & Periódico \\
\hline $\begin{array}{l}\text { Merlijn van Hulst \& Sierk } \\
\text { Ybema }\end{array}$ & 2020 & $\begin{array}{l}\text { From what to where: a setting-sensitive } \\
\text { approach to organizational storytelling }\end{array}$ & $\begin{array}{l}\text { Organization } \\
\text { Studies }\end{array}$ \\
\hline $\begin{array}{l}\text { Anne M. Kok, Frank G. A. de } \\
\text { Bakker \& Peter Groenewegen }\end{array}$ & 2019 & $\begin{array}{l}\text { Sustainability struggles: conflicting } \\
\text { cultures and incompatible logics }\end{array}$ & Business $\mathcal{E}$ Society \\
\hline $\begin{array}{l}\text { Christoph Barmeyer, Eric } \\
\text { Davoine \& Peter Stokes }\end{array}$ & 2019 & $\begin{array}{l}\text { When the 'well-oiled machine' meets the } \\
\text { 'pyramid of people:' Role perceptions } \\
\text { and hybrid working practices of middle } \\
\text { managers in a binational organization } \\
\text { - ARTE }\end{array}$ & $\begin{array}{l}\text { International Journal } \\
\text { of Cross-Cultural } \\
\text { Management }\end{array}$ \\
\hline $\begin{array}{l}\text { Andreina Bruno, Giuseppi- } \\
\text { na Dell'Aversana \& Gloria } \\
\text { Guidetti }\end{array}$ & 2018 & $\begin{array}{l}\text { Developing organizational competences } \\
\text { for conflict management: the use of the } \\
\text { prisoner's dilemma in higher education }\end{array}$ & $\begin{array}{l}\text { Frontiers in Psy- } \\
\text { chology }\end{array}$ \\
\hline $\begin{array}{l}\text { Parisa Dashtipour \& Bénédicte } \\
\text { Vidaillet }\end{array}$ & 2017 & $\begin{array}{l}\text { Work as affective experience: the contri- } \\
\text { bution of Christophe Dejours' 'psychody- } \\
\text { namics of work' }\end{array}$ & Organization \\
\hline Susan L.T. Ashley & 2016 & $\begin{array}{l}\text { Re-colonizing spaces of memorializing: } \\
\text { the case of the Chattri Indian Memorial, } \\
\text { UK }\end{array}$ & Organization \\
\hline $\begin{array}{l}\text { Kaarina Mönkkönen \& Anu } \\
\text { Puusa }\end{array}$ & 2015 & $\begin{array}{l}\text { From disunited to joint action: dialogue } \\
\text { reflecting the construction of organiza- } \\
\text { tional identity after a merger }\end{array}$ & SAGE Open \\
\hline $\begin{array}{l}\text { John Finch, Shiming Zhang \&, } \\
\text { Susi Geiger }\end{array}$ & 2013 & $\begin{array}{l}\text { Managing in conflict: how actors distrib- } \\
\text { ute conflict in an industrial network }\end{array}$ & $\begin{array}{l}\text { Industrial Marketing } \\
\text { Management }\end{array}$ \\
\hline
\end{tabular}

Fonte: a autoria (2021).

Após a leitura e destaque de informações, no Quadro 5 especificou-se o contexto em que os trabalhos selecionados foram desenvolvidos, considerando que aspectos contextuais são muito importantes no desencadear de emoções: 
Quadro 5: Informações dos trabalhos selecionados para análise

\begin{tabular}{|c|c|c|c|c|}
\hline Autor/Ano & $\begin{array}{l}\text { No de } \\
\text { casos }\end{array}$ & País & Organização & $\begin{array}{l}\text { Nível de } \\
\text { análise }\end{array}$ \\
\hline $\begin{array}{l}\text { Merlijn van Hulst \& Sierk } \\
\text { Ybema } \\
(2020)\end{array}$ & 1 & Holanda & Organização policial & $\begin{array}{l}\text { Nível individual/ } \\
\text { grupal }\end{array}$ \\
\hline $\begin{array}{l}\text { Anne M. Kok, Frank G. A. } \\
\text { de Bakker \& Peter Groe- } \\
\text { newegen (2019) }\end{array}$ & 1 & Alemanha & Banco & $\begin{array}{l}\text { Nível individual/ } \\
\text { grupal }\end{array}$ \\
\hline $\begin{array}{l}\text { Christoph Barmeyer, Eric } \\
\text { Davoine \& Peter Stokes } \\
(2019)\end{array}$ & 1 & $\begin{array}{l}\text { França e } \\
\text { Alemanha }\end{array}$ & $\begin{array}{l}\text { Organização bina- } \\
\text { cional }\end{array}$ & $\begin{array}{l}\text { Nível individual/ } \\
\text { gerentes }\end{array}$ \\
\hline $\begin{array}{l}\text { Andreina Bruno, Giuseppi- } \\
\text { na Dell' Aversana \& Gloria } \\
\text { Guidetti } \\
\text { (2018) }\end{array}$ & 1 & Itália & $\begin{array}{l}\text { Universidade - foco } \\
\text { em um programa de } \\
\text { mestrado }\end{array}$ & $\begin{array}{l}\text { Nível individual/ } \\
\text { estudantes de } \\
\text { mestrado }\end{array}$ \\
\hline $\begin{array}{l}\text { Parisa Dashtipour \& Béné- } \\
\text { dicte Vidaillet (2017) }\end{array}$ & 1 & Inglaterra & Hospital & $\begin{array}{l}\text { Nível individual/ } \\
\text { profissionais espe- } \\
\text { cíficos do hospital }\end{array}$ \\
\hline Susan L.T. Ashley (2016) & 1 & Reino Unido & $\begin{array}{l}\text { Turismo/herança } \\
\text { cultural }\end{array}$ & $\begin{array}{l}\text { Nível organizacio- } \\
\text { nal/ grupo como } \\
\text { unidade de análise }\end{array}$ \\
\hline $\begin{array}{l}\text { Kaarina Mönkkönen \& } \\
\text { Anu Puusa } \\
(2015)\end{array}$ & 1 & Finlândia & $\begin{array}{l}\text { Empresa do setor } \\
\text { público vinculada } \\
\text { ao Ministério da } \\
\text { Economia e Trabalho } \\
\text { anteriormente divi- } \\
\text { dida em } 3 \text { escritórios } \\
\text { governamentais com } \\
\text { diferentes expertises: } \\
\text { trabalho, economia, } \\
\text { transporte e meio } \\
\text { ambiente. }\end{array}$ & $\begin{array}{l}\text { Nível individual/ } \\
\text { grupal dentro do } \\
\text { contexto da organi- } \\
\text { zação. }\end{array}$ \\
\hline $\begin{array}{l}\text { John Finch, Shiming Zhang } \\
\& \text {, Susi Geiger (2013) }\end{array}$ & 5 & $\begin{array}{l}\text { Organizações } \\
\text { atuantes em } \\
\text { diversos paí- } \\
\text { ses europeus. }\end{array}$ & $\begin{array}{l}\text { Indústrias de gás e } \\
\text { óleo }\end{array}$ & $\begin{array}{l}\text { Nível organizacio- } \\
\text { nal/ trabalhadores } \\
\text { como unidade de } \\
\text { análise. }\end{array}$ \\
\hline
\end{tabular}

Fonte: elaborado pela autoria com base nos artigos selecionados (2021).

Realizada a seleção e anotação de informações dos artigos finais, seguiu-se à aplicação dos passos seguintes da metassíntese, tendo em mente o objetivo de compreender a forma como as emoções são 
abordadas em estudos de caso qualitativos interligados a estudos organizacionais.

\section{Passo 4: Extração e codificação de dados}

Os dados utilizados na metassíntese não são originados de dados brutos resultantes dos estudos selecionados, mas, sim, de insights gerados pelo pesquisador durante a sua análise. A metassíntese, portanto, tem como finalidade a sistematização de pontos que permitam ao pesquisador ter à sua disposição um banco de dados com os quais discute os seus interesses de pesquisa. Diante dessa série de trabalhos podem haver pesquisas que auxiliem o entendimento do campo, por isso, as codificações são importantes no processo (HOON, 2013).

Em suas delimitações, Hoon (2013) destaca que é necessário elaborar codificações que sejam claras e que facilitem a procura de informações em períodos de buscas. Essas codificações devem refletir os pressupostos do pesquisador, que pode criar códigos conforme a sua vontade e reflexão. Os códigos, todavia, devem trazer consigo e à seleção dos trabalhos a qualidade necessária para o estudo.

Seguindo o formulário de codificação desenvolvido por Hoon (2013), no Quadro 6 são expostos os códigos utilizados nesta pesquisa:

Quadro 6: Códigos utilizados na pesquisa

\begin{tabular}{|l|l|}
\hline \multicolumn{1}{|c|}{ Grupo de código } & \multicolumn{1}{|c|}{ Códigos } \\
\hline Detalhes gerais do estudo & Autor(es) \\
& Título \\
& Periódico \\
& Data da publicação \\
& Tipo de estudo \\
\hline O que os autores pretendem alcançar? & Objetivo geral \\
& Questão de pesquisa \\
& Contribuições \\
\hline Enquadramento teórico & $\begin{array}{l}\text { Como o estudo aborda as emoções dentro do contexto } \\
\text { de estudos organizacionais } \\
\text { Conceitos/compreensão de emoções } \\
\end{array}$ \\
& Tipo de emoção abordada \\
\hline
\end{tabular}




\begin{tabular}{|l|l|}
\hline \multicolumn{1}{|c|}{ Grupo de código } & \multicolumn{1}{|c|}{ Códigos } \\
\hline $\begin{array}{l}\text { Definição do contexto em que o estudo foi } \\
\text { realizado }\end{array}$ & $\begin{array}{l}\text { País } \\
\text { Contexto de pesquisa } \\
\text { Setor } \\
\text { Local da pesquisa } \\
\text { Delineamento da pesquisa }\end{array}$ \\
\hline Metodologia & $\begin{array}{l}\text { Projeto de pesquisa (ex.: estudo de caso histórico, indu- } \\
\text { tivo, construção de teoria a partir de estudo de caso) } \\
\text { Abordagem (ex.: construção de teoria, elaboração de }\end{array}$ \\
teoria) \\
Unidade de análise \\
Número de casos investigados \\
Estratégia de amostragem
\end{tabular}




\begin{tabular}{|c|c|}
\hline Grupo de código & Códigos \\
\hline Outros aspectos & $\begin{array}{l}\text { Qual a relevância do estudo para o problema investi- } \\
\text { gado? } \\
\text { Qual a validade deste estudo? } \\
\text { Quais as informações encontram-se inconsistentes? } \\
\text { Comentários adicionais }\end{array}$ \\
\hline
\end{tabular}

Fonte: adaptado de Hoon (2013).

Após a codificação dos dados, iniciou-se a análise de cada nível específico dos estudos de casos qualitativos, analisando-se, principalmente, os dados que poderiam se relacionar com a maneira como as emoções são trabalhadas na área de estudos organizacionais. Com isso, pretendeu-se criar uma síntese a respeito de todos os casos de maneira a permitir a produção de um conjunto de reflexões a respeito dos questionamentos e objetivos delimitados para esta metassíntese. Os resultados são apresentados no próximo passo.

\section{Passo 5: Análise em nível específico de cada caso}

O objetivo de uma metassíntese é identificar os aspectos de cada estudo selecionado, os quais possam contribuir para o desenvolvimento e aprimoramento teórico. Com tal conceito em mente apresentam-se as especificidades de cada um dos oito artigos selecionados para análise final, conforme procedimentos descritos por Hoon (2013). Considera-se, também, conforme descrito no protocolo deste estudo, disponível no Quadro 1, que o propósito estabelecido para este passo visa identificar e analisar a forma como as emoções são abordadas em cada caso.

Os casos são analisados individualmente e, para a realização da análise, levou-se em consideração o conceito de emoção apresentado por Barsade e Gibson (2007), para quem as emoções englobam processos afetivos que abrangem uma gama de sentimentos da experiência individual. Estados de sentimento são emoções "do momento" provindas de experiências afetivas de curta duração, enquanto traços de sentimento são emoções mais estáveis que demonstram tendências de se sentir e agir de determinado modo. 
O primeiro estudo a se destacar é o de Van Hulst e Ybema (2020) que teve como objetivo delimitado trazer à discussão aspectos contextuais de narrativas e storytelling. Os resultados foram norteados por quatro questões: (1) O que faz com que um evento possa ser contado? (2) O que desencadeia a sua narração? (3) Qual a forma que a narração da história assume? (4) Que trabalho ele realiza? Utilizando dados etnográficos coletados sobre a narração de histórias no trabalho cotidiano da Polícia, os autores destacaram alguns pontos, dentre eles os voltados às emoções. Nesse sentido, ressaltaram que as histórias podem, muitas vezes, provocar emoções, contendo, também, explicações e avaliações sobre a ocorrência. As histórias aqui mencionadas ajudaram os participantes a falar sobre coisas e emoções que eles próprios não haviam experimentado e, com os fatos narrados, desenvolveu-se sensibilidade para o policiamento.

Já o estudo de Kok, Bakker e Groenewegen (2019) teve como objetivo entender a forma como as organizações lidam internamente com a crescente pressão institucional para se tornarem mais responsáveis socialmente e, também, captar o papel da cultura organizacional e das lógicas institucionais nesse contexto. Os resultados apontam que o processo de desenvolvimento de políticas de sustentabilidade não ocorre de forma isolada diante das diferenças subculturais e lógicas institucionais. Nas reuniões observadas pelos pesquisadores, frustrações e emoções eram aparentes, sendo que um dos achados da pesquisa destacou que as emoções possuíam importante papel na ruptura, criação e manutenção de instituições, concordando com o que fora exposto por Voronov e Vince (2012). Diante disso, a sugestão dos autores foi dedicar maior atenção ao papel das emoções, especialmente às individuais no interior de processos organizacionais - no caso deste artigo, aos institucionalizados e decorrentes da cultura da própria organização.

Em seguida analisou-se o estudo de Barmeyer, Davoine e Stokes (2019). O objetivo delimitado para este estudo de caso foi examinar as representações da gerência média de uma organização e as funções gerenciais num contexto organizacional bicultural específico. $\mathrm{O}$ foco do artigo foi uma organização binacional e, diante do objetivo delimitado, os principais resultados voltados à emoção destacaram que os supervisores considerados motivadores tinham seus comportamentos associados à comunicação e negociação de objetivos claros, mas não à relação interpessoal e emocional. Os resultados destacaram a necessidade de ajuste de um estilo de liderança que 
introduzisse mais emoção em seu contexto.

O estudo analisado na sequência foi o de Bruno, Dell'Aversana e Guidetti (2018), cujo objetivo foi explorar: (1) as características significativas do "Prisoner's Dilemma Game" (PDG) usado em uma chave afetivo-emocional no ensino superior; e (2) os resultados do aprendizado que o PDG permitiu ativar nos participantes em relação ao desenvolvimento de habilidades organizacionais para a análise de conflitos. Com foco na simulação como estudo de caso, os autores verificaram que o jogo permitiu que se recriassem as condições de um conflito. No caso, o principal aspecto do jogo em si esteve voltado à resolução de um conflito. A emoção foi trazida como reflexo de conflitos, podendo, inclusive, surgir nesse cenário. No final, os autores destacaram que em conflitos organizacionais, as emoções que tendem a se destacar são negativas, como, por exemplo: decepção e vergonha.

Outro artigo analisado foi o de Dashtipour e Vidaillet (2017), cujo objetivo foi discutir os afetos associados ao próprio processo de trabalho, sendo emoções e afetos tratados como sinônimos. O estudo destaca duas contribuições voltadas à emoção: (1) os afetos associados à atividade de trabalho; e (2) ampliação das abordagens críticas nos estudos organizacionais, demonstrando a centralidade do trabalho na vida afetiva do sujeito. $\mathrm{O}$ argumento principal é que não é preciso ser contra o trabalho para ser crítico em relação às organizações de trabalho.

O sexto artigo é o de Ashley (2016), que inspeciona as formas como os espaços de memorialização de guerra são organizados e reorganizados a partir de atividades oficiais e não oficiais de criação de significados. O objetivo foi contribuir para a discussão do "valor" da memorização, examinando um espaço multifacetado de lembrança e comemoração: o Chattri Indian Memorial construído próximo de Brighton, no Reino Unido. Destaca-se que a memorialização funciona como um processo organizacional que constitui e valida o significado cultural. A emoção, no entanto, possui grande influência nesse processo, pois influencia, principalmente, a atribuição de valor e significado de algo. O novo significado atribuído ao Memorial demonstrou o potencial da memorização como uma atividade emocional que facilita o que a autora coloca como quebra dos discursos autorizados.

O penúltimo estudo de caso ora analisado é o de Mönkkönen e Puusa (2015), que examina uma organização pública que passa 
por uma mudança organizacional. Descreve, então, o processo de construção da identidade organizacional após uma fusão, utilizando um modelo que descreve formas identificadas de interação: (a) formalmente juntos; (b) interação unidirecional; (c) justaposições; (d) construção de pontos em comum; e (e) o estado de ação conjunta. Os elementos emocionais foram vistos como característica da identidade organizacional, pois descrevem a intensidade como as pessoas acreditam na natureza única e distintiva da organização em que atuam, todavia, as emoções em si só foram abordadas no referencial teórico.

Por fim, o estudo de Finch, Zhang e Geiger (2013) destacou que pesquisas anteriores examinaram o conflito como uma ameaça às relações comerciais estabelecidas e às trocas comerciais, baseando-se em teorias e conceitos desenvolvidos em estudos de organização. O objetivo formulado para este estudo de caso examinou casos de conflitos em relacionamentos do setor de serviços da indústria de petróleo e gás, focando em interesses e recursos. Os autores afirmam que as emoções possuem certa influência no contexto de gerenciamento de conflitos, entretanto, poucas evidências foram encontradas quanto a aspectos críticos relacionados à continuação das relações comerciais, ou seja, as emoções possuem influência, mas se desencadeiam em função do contexto. Os atores experimentaram conflitos enquanto se adaptaram às mudanças em seu ambiente de negócios, modificando seus papéis nessa rede.

\section{Passo 6: Síntese no nível de estudo}

Na sexta etapa de uma metassíntese as informações coletadas em nível individual de cada artigo permitem compreender a forma como as emoções estão sendo abordadas em estudos organizacionais e as suas relações. Para uma melhor visualização dos dados mencionados no passo anterior, e destacando o modo como as emoções foram tratadas nos estudos, os artigos analisados e discutidos serão resumidos de acordo com algumas características: o contexto do estudo de caso, o tipo de emoção utilizada e a sua conexão com estudos organizacionais. 


\section{Quadro 7: Características dos estudos}

\begin{tabular}{|c|c|c|c|}
\hline Artigo & Contexto & $\begin{array}{l}\text { Tipo de } \\
\text { emoção } \\
\text { utilizada }\end{array}$ & $\begin{array}{c}\text { Conexão com estudos } \\
\text { organizacionais }\end{array}$ \\
\hline $\begin{array}{l}\text { Hulst \& Ybema } \\
(2020)\end{array}$ & $\begin{array}{l}\text { Cotidiano de } \\
\text { policiais }\end{array}$ & Emoção geral & $\begin{array}{l}\text { Relaciona-se às narrativas contadas } \\
\text { dentro de organizações com fatores } \\
\text { contextuais, como as emoções que se } \\
\text { desencadeiam nesse ambiente. }\end{array}$ \\
\hline $\begin{array}{l}\text { Kok, Bakker e Groe- } \\
\text { newegen (2019) }\end{array}$ & $\begin{array}{l}\text { Organização do } \\
\text { setor financeiro }\end{array}$ & Emoção geral & $\begin{array}{l}\text { Coloca-se em pauta o papel das lógicas } \\
\text { institucionais e da cultura em relação a } \\
\text { processos de mudança dentro das orga- } \\
\text { nizações. Descobre-se, aqui, as emoções } \\
\text { como fator influente no processo. }\end{array}$ \\
\hline $\begin{array}{l}\text { Barmeyer, Davoine e } \\
\text { Stokes (2019) }\end{array}$ & $\begin{array}{l}\text { Organização } \\
\text { binacional }\end{array}$ & Emoção geral & $\begin{array}{l}\text { O estudo engloba as emoções dentro de } \\
\text { uma organização binacional, destacando } \\
\text { a forma como as emoções podem se } \\
\text { atrelar a aspectos culturais. }\end{array}$ \\
\hline $\begin{array}{l}\text { Bruno, Aversana e } \\
\text { Guidetti (2018) }\end{array}$ & $\begin{array}{l}\text { Simulação em } \\
\text { contexto acadê- } \\
\text { mico }\end{array}$ & $\begin{array}{l}\text { Emoção geral, } \\
\text { decepção e } \\
\text { vergonha }\end{array}$ & $\begin{array}{l}\text { São trazidos aspectos de estudos orga- } \\
\text { nizacionais quando colocada em pauta a } \\
\text { resolução de conflitos organizacionais. }\end{array}$ \\
\hline $\begin{array}{l}\text { Dashtipour e Vidai- } \\
\text { llet (2017) }\end{array}$ & $\begin{array}{l}\text { Hospital conside- } \\
\text { rado renomado, } \\
\text { porém não } \\
\text { identificado }\end{array}$ & Afeto & $\begin{array}{l}\text { Coloca-se em pauta a teoria psicodinâ- } \\
\text { mica de Christophe Dejours juntamente } \\
\text { com o fato de que os afetos podem estar } \\
\text { presentes em processos organizacionais, } \\
\text { com destaque para as suas relevâncias. }\end{array}$ \\
\hline Ashley (2016) & $\begin{array}{l}\text { Chattri Indian Me- } \\
\text { morial construído } \\
\text { nas proximida- } \\
\text { des de Brighton, } \\
\text { no Reino Unido }\end{array}$ & Emoção geral & $\begin{array}{l}\text { A relação com estudos organizacionais é } \\
\text { vista principalmente quando as caracte- } \\
\text { rísticas do memorial são destacadas. }\end{array}$ \\
\hline $\begin{array}{l}\text { Mönkkönen e Puusa } \\
\text { (2015) }\end{array}$ & $\begin{array}{l}\text { Uma organização } \\
\text { pública em perío- } \\
\text { do de mudança } \\
\text { organizacional }\end{array}$ & Emoção geral & $\begin{array}{l}\text { Um ponto que chamou a atenção em } \\
\text { relação a estudos organizacionais vol- } \\
\text { tou-se à maneira como a emoção é abor- } \\
\text { dada. Ela é vista como fator influente à } \\
\text { identificação organizacional diante do } \\
\text { processo de mudança organizacional. }\end{array}$ \\
\hline $\begin{array}{l}\text { Finch, Zhang e } \\
\text { Geiger (2013) }\end{array}$ & $\begin{array}{l}\text { Indústria de } \\
\text { petróleo e gás }\end{array}$ & Emoção geral & $\begin{array}{l}\text { Estudos organizacionais focando-se em } \\
\text { conflitos organizacionais. }\end{array}$ \\
\hline
\end{tabular}

Fonte: a autoria (2021). 
Percebeu-se que todos os estudos selecionados cumprem os requisitos de seleção, evidenciando a forma como a emoção está sendo utilizada em pesquisas de estudo de caso em estudos organizacionais. A recomendação de Hoon (2013) para este passo é de que se apresente uma figura lógica que permita melhor visualização da temática a ser abordada. A figura, contudo, será apresentada no passo seguinte.

\section{Passo 7: Criação de teoria pela metassíntese}

Hoon (2013) salienta que um passo de contribuição da metassíntese refere-se à construção de teoria que permita ao pesquisador se aproximar dos fenômenos estudados. O propósito é contribuir com o aprofundamento e interesse em se colocar o fenômeno da emoção em estudos organizacionais.

Nesse sentido, é importante ressaltar que, conforme anteriormente indicado pela bibliografia pesquisada, não há uma literatura específica a respeito de emoções na área de estudos organizacionais (GONZÁLEZ REY, 2003; JOST; BULGACOV; CAMARGO, 2018). Os estudos encontrados nesta metassíntese ressaltam ainda mais esse fato pois, como salientado na análise individual dos artigos, as organizações e as próprias pesquisas em si encaram o fenômeno das emoções como algo secundário dentro de seus contextos por mais que interfiram e delas emerjam.

Partindo das análises individuais de cada artigo selecionado, foi possível identificar padrões específicos, a exemplo do caso do tipo de emoção comumente utilizada, a maneira como a emoção é discutida e a forma como a área de estudos organizacionais tem abordado esse conceito em sua conjuntura, configurando o tema proposto por essa metassíntese. Em vista disso foi possível estabelecer uma relação com os elementos em comum que surgiram em decorrência das análises específicas. Essa relação é destacada na Figura 1 e explicada a seguir: 
Figura 1: Relação entre emoções e estudos organizacionais

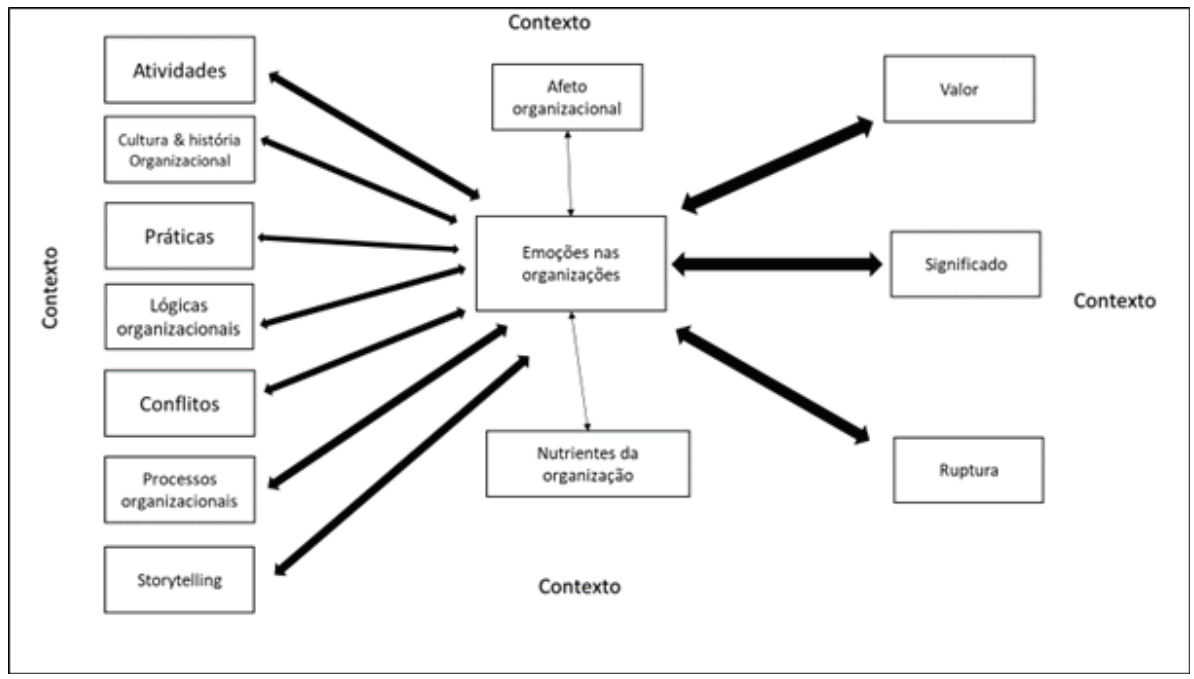

Fonte: a autoria (2021).

Verificou-se que não há um conceito único de emoções presente nos estudos, todavia, o conceito mais utilizado refere-se àquele em que não se menciona alguma emoção específica na análise. $\mathrm{O}$ que se buscou delinear na Figura 1 foi o fato de que as emoções influenciam e são influenciadas pelo contexto organizacional. O contexto, por sua vez, sofre interferência de diversos elementos presentes no cotidiano das organizações, contudo, ao influenciar e ser influenciado pelas emoções, desencadeia um papel relevante, fazendo com que as emoções sejam um dos fatores que permitem a existência de afeto pelas organizações e, de certa forma, até o seu nutrimento. Além disso, foi possível verificar que as emoções desencadeiam valor, ruptura e significado com o que ocorre no interior das organizações e, de acordo com os estudos selecionados, é dessa maneira que esse fenômeno é abordado em estudos de casos organizacionais. Apesar de considerar o contexto de cada estudo, não se encontrou uma única razão que esclareça tal influência, tampouco uma justificativa a respeito de qual fator (a própria emoção ou o próprio contexto) seria o principal motivante e iniciaria essa conexão entre os dois conceitos. 
Os estudos salientam a importância das emoções nas organizações, contudo, apenas uma das pesquisas encontradas colocou nelas o seu foco principal e, ao fazê-lo, utilizou o termo "afeto" como sinônimo. Todas as outras pesquisas trouxeram as emoções como ponto emergente do campo e de interferência ao desenvolvimento organizacional, bem como dos integrantes dessas organizações, o que traz a necessidade de desenvolvimento de um conceito e de pesquisas que possam indicar a relevância das emoções no contexto organizacional.

Um dos achados principais desta metassíntese refere-se à necessidade de abordar as emoções como um dos elementos primordiais em estudos que têm o indivíduo num nível fundamental de análise. Dos oito artigos analisados, apenas o estudo de Dashtipour e Vidaillet (2017) evidenciou essa abordagem, no entanto, como visto nas análises individuais, essa utilização colocou o conceito de afeto como um dos sinônimos de emoções. Devido as emoções abrangerem um grande escopo de sentimentos e estarem incluídas na definição de processos afetivos, é importante ressaltar os motivos que levam à utilização de um termo em virtude do outro, bem como as suas diferenças, de maneira que não ocorra confusão quanto aos significados dos termos.

Cabe salientar, portanto, que esta metassíntese contribui com a teoria ao explorar o modo como as emoções são abordadas em estudos organizacionais, apontando outras perspectivas a serem exploradas diante das lacunas encontradas. A síntese dos artigos demonstra que as emoções e o contexto organizacional se relacionam e, dependendo das especificidades do contexto, diferentes são as emoções que podem se apresentar. Apesar de a maioria dos artigos abordarem as emoções de forma geral, é interessante, também, explorar emoções específicas que possam se desencadear no interior das organizações.

Com o destaque a ser dado às emoções, um novo olhar pode ser empreendido a respeito da dinâmica organizacional, ressaltando a importância do indivíduo dentro dos processos a serem ali desenvolvidos, tendo em vista que, em termos práticos, mesmo se emoções negativas existirem, se as emoções positivas tomarem maior espaço, mais positivos serão os resultados organizacionais. Em relação 
aos aspectos teóricos, as emoções permitirão um novo olhar sobre as dimensões humanas existentes no interior das organizações.

\section{Passo 8: Discussão}

Pesquisas que utilizam o termo "emoções" na área de estudos organizacionais ainda são recentes e encontram-se em desenvolvimento (ASHKANASY, 2003; JOST; BULGACOV; CAMARGO, 2018). É possível verificar, entretanto, que esse aspecto está se alterando com mais rapidez devido à visualização por parte dos pesquisadores de que as emoções são relevantes e influentes dentro das organizações (ASHKANASY, 2003). Esse aspecto é perceptível nesta metassíntese, considerando que em todas as bases pesquisadas viu-se que desde o ano de 2013 a temática vem sendo explorada enquanto formato de estudo de caso.

As definições clássicas de emoções são termos que também podem abranger os sentimentos dos indivíduos, diferenciando-se de outros sinônimos comuns, como o caso de "humor" quanto à sua duração (BARSADE; GIBSON, 2007; BRODY; HALL; STOKES, 2016). Devido à sua amplitude, o pesquisador pode escolher utilizá-las de maneira geral ou específica (BARSADE; GIBSON, 2007) e, como visto nos estudos selecionados, estudar as emoções de forma mais geral vem sendo utilizado apesar de haver especificidades no estudo de Bruno, Dell' Aversana e Guidetti (2018) e também de ter sido abordada como afeto por Dashtipour e Vidaillet (2017).

Outra curiosidade a se destacar é de que apenas um dos estudos utilizou a estratégia de estudo de casos múltiplos, enquanto todos os demais tratavam de casos únicos em que os pesquisadores optaram por entrevistar pessoas de uma mesma organização. Mesmo tendo enfoque em pessoas das organizações, na maioria dos estudos as emoções eram temas emergentes e não o objetivo principal a ser discutido no trabalho. Por sua relevância, influência e abrangência, as emoções em si abriam espaço no campo da pesquisa sob diferentes perspectivas e contextos, revelando serem fenômenos que merecem o devido destaque no campo, não somente com o olhar provindo da Psicologia e, sim, de gestores, pesquisadores organizacionais e dos próprios integrantes da organização. Esse resultado, contudo, também pode ser uma estratégia de estudo de caso em que, nos 
casos em análise, a organização era o caso a ser considerado e não o indivíduo em si, sendo este apenas um dos níveis de análise utilizados pelos autores.

Por consequência dessa emergência em meio a outras temáticas, não foi possível explorar nesta metassíntese os aspectos relacionados ao gênero do indivíduo e às diferenças na expressão de suas emoções, como destacado por Brody, Hall e Stokes (2016). Viu-se, contudo, que aspectos sociais, culturais e situações específicas, conforme destacado pelos autores, acabam se entrelaçando com as emoções e os estudos organizacionais.

Procurou-se desenvolver na Figura 1, um esquema que demonstre como a emoção ocorre dentro da área dos estudos organizacionais, todavia, o ponto de maior destaque refere-se ao contexto organizacional, sendo este o foco a ser tratado nos estudos. A emoção vincula-se aos significados e necessidades de um indivíduo não só na sua trajetória, como salientado por González Rey (2003), mas, sim, ao trabalho e organização por completo.

Os artigos, ao destacarem a emergência das emoções ao entrarem no contexto organizacional, destacam que elas são mais perceptíveis diante de processos sociais e nas relações que o indivíduo constitui em nível pessoal e grupal, bem como diante de aspectos históricos e culturais (JOST; BULGACOV; CAMARGO, 2018).

As lacunas mencionadas neste estudo também podem ser consideradas consequências da novidade do tema "emoções" na área de estudos organizacionais, tendo em vista que apenas recentemente tem-se adereçado os estudos de tal temática a perspectivas que não envolvem as vidas pessoais dos indivíduos (LIVELY; WEED, 2014). Com a análise individual dos artigos foi possível verificar que as emoções são importantes quando se coloca em pauta assuntos sociais - como é o caso de um dos pontos de estudos organizacionais - concordando com o exposto por Hochschild (1990).

Apesar dos gaps e das possibilidades do seu preenchimento na área de estudos organizacionais, percebeu-se que as emoções no ambiente organizacional não devem ser tratadas apenas como consequência de uma série de fatores contextuais e, sim, como um elemento que pode interferir no desenvolvimento de estudos organizacionais, sendo relevantes, inclusive, no avanço da própria 
pesquisa. O que se pode absorver desta metassíntese, portanto, é que há necessidade de maior aprofundamento e exploração da temática na área dos estudos organizacionais, com destaque à magnitude que as emoções possuem em todo esse contexto e como ele também pode nelas interferir.

\section{CONSIDERAÇõES FINAIS}

No presente estudo procurou-se analisar a forma como as emoções são abordadas em estudos organizacionais. Utilizou-se, para tanto, a técnica da metassíntese, especificamente em estudos de casos qualitativos - um dos critérios mencionados por Hoon (2013). A opção por colocar as emoções em evidência deu-se em consequência da recente utilização do fenômeno em estudos organizacionais. A técnica de metassíntese permitiu relacionar a temática numa perspectiva mais ampla, bem como a sua forma de abordagem, permitindo melhor compreensão a respeito de sua utilização.

As emoções estão presentes em diferentes contextos, como na análise de storytelling (VAN HULST; YBEMA, 2020), em questões referentes às lógicas organizacionais incompatíveis e influências culturais (KOK; BAKKER; GROENEWEGEN, 2019), nas práticas organizacionais (BARMEYER; DAVOINE; STOKES, 2019), no gerenciamento de conflitos (BRUNO; DELL'AVERSANA; GUIDETTTI, 2018; FINCH; ZHANG; GEIGER, 2013), nas experiências afetivas em ambiente de trabalho (DASHTIPOUR; VIDAILLET, 2017); nas questões culturais e históricas (ASHLEY, 2016), e na construção da identidade organizacional (MÖNKKÖNEN; PUUSA, 2015).

É importante destacar que uma metassíntese tem por objetivo criar ou estender teoricamente uma concepção por meio da análise comparativa entre casos. Considerando que as emoções podem ser analisadas sob diferentes lentes, a metassíntese desenvolvida propiciou melhor entendimento a respeito da forma como elas podem ocorrer num cenário organizacional. Percebeu-se que o contexto é um elemento importante e influente a ser considerado, conforme mostrou a Figura 1. As emoções influenciam e são influenciadas pelo contexto, e cabe aos pesquisadores da área colocá-las como um dos elementos principais a serem analisados e não apenas como aspectos secundários em estudos das organizações. 
A principal contribuição desta pesquisa é sugerir uma alteração na forma como as emoções atualmente são abordadas pelos estudos organizacionais, propondo que, mesmo diante de casos em que o foco seja a organização por completo, se leve em consideração a emoção como um dos fatores primordiais em seus respectivos contextos. Ou seja, ao estudar o fator humano dentro das organizações, mesmo diante de outros temas, considerando as epistemologias e ontologias, é interessante ao pesquisador relacionar alguns aspectos que envolvem o indivíduo a emoções no interior das organizações. Acredita-se que dessa maneira se possa evidenciar a importância das emoções nas organizações, bem como a sua influência dentro de tal cenário. Ao colocar essa discussão em pauta, este estudo abre as portas para pesquisas futuras, incentivando novos olhares e vertentes aos estudos organizacionais.

Propõe-se, em virtude da inquietação da pesquisadora, pesquisas futuras que explorem a maneira como as emoções influenciam o comportamento dos indivíduos dentro das organizações, a tomada de decisão, as iniciativas empreendedoras, o próprio envelhecimento no trabalho, dentre outras temáticas que discutam a importância que as pessoas possuem no contexto organizacional. Em virtude da ausência de pesquisas com os termos de buscas pesquisados em bases de dados nacionais, sugere-se contribuições teóricas para maior discussão a respeito da temática na literatura brasileira. Em termos práticos, que ao se discutir tal temática, se desenvolva maior sensibilidade tanto em gestores quanto nos próprios agentes atuantes em organizações.

Por fim, cabe mencionar as limitações existentes nesta pesquisa, como indica Hoon (2013). Inicialmente, ressalta-se que a leitura e a codificação dos dados foi realizada por apenas um único pesquisador e, de acordo com o exposto por Hoon (2013), mais de um pesquisador atuante na presente etapa amplia a confiabilidade dos resultados. As leituras, releituras e sistematização dos trabalhos, todavia, juntamente com a elaboração de todas as etapas previstas por Hoon (2013), ajudou a minimizar os vieses que poderiam existir em consequência de tal limitação.

Além do exposto, foram utilizadas três distintas palavras-chave em seis cadeias de busca, contudo, apenas duas eram nacionais e 
não geraram resultados, apesar de serem amplas e refletirem a abordagem proposta por Hoon (2013). Seguindo o protocolo da autora, objetivou-se reduzir as limitações metodológicas da abordagem de metassíntese, de maneira que fosse possível replicar o estudo, bem como gerar contribuições significativas ao campo.

\section{REFERÊNCIAS}

ASHKANASY, N. M. Multi-level issues in organizational behavior and strategy, 2003.

ASHLEY, S. L. T. Re-colonizing spaces of memorializing: the case of the Chattri Indian Memorial, UK. Organization, v. 23, n. 1, 2016, pp. 29-46.

BARMEYER, C.; DAVOINE, E.; STOKES, P. When the "well-oiled machine" meets the "pyramid of people": Role perceptions and hybrid working practices of middle managers in a binational organization-ARTE. International Journal of Cross Cultural Management, v. 19, n. 3, 2019, pp. 251-272.

BARRETT, L. F.; LEWIS, M.; HAVILAND-JONES, J. M. (Eds.). Handbook of emotions. Guilford Publications, 2016.

BARSADE, S. G.; GIBSON, D. E. Why does affect matter in organizations? Academy of management perspectives, v. 21, n. 1, 2007, pp. 36-59.

BRAMMING, P.; JOHNSEN, R. Love will tear us apart-transformational leadership and love in a call center. European Journal of International Management, v. 5, n. 1, 2011, pp. 80-95.

BRODY, L. R.; HALL, J. A.; STOKES, L. R. Gender and emotion: theory, findings and context. Handbook of emotions, v. 4, 2016, pp. 369-392.

BRUNO, A.; DELL'AVERSANA, G.; GUIDETTI, G. Developing organizational competences for conflict management: the use of the prisoner's dilemma in higher education. Frontiers in psychology, v. 9, 2018.

BURCH, G. F. et al. Unraveling the complexities of empathy research: a multi-level model of empathy in organizations', emotions and organizational governance (research on emotion in organizations), v. 12, 2016.

CAMARGO, R. A. M. M.; LOURENÇO, M. L.; FERREIRA, J. M. Entrepreneurial women in Brazil: what are their fears? Revista Brasileira de Gestão de Negócios, v. 20, n. 2, 2018, pp. 178-193.

CLEGG, S. R.; HARDY, C. Introdução: organização e estudos organizacionais. In: CLEGG, S. C.; HARDY, C.; NORD, W. (Orgs.). Handbook de estudos organizacionais: modelos de análise e novas questões em estudos organizacionais, v. 1, 1999.

CRUZARA, G. et al. The impact of digital transformation and industry 4.0 on the aspects of value: evidence from a meta-synthesis. Contextus - Revista Contemporânea de Economia e Gestão, [s.1.], v. 18, 29 jun. 2020, pp. 92-106. Universidade Federal do Ceará. http://dx.doi. org/10.19094/contextus.2020.43717. 
DASHTIPOUR, P.; VIDAILLET, B. Work as affective experience: the contribution of Christophe Dejours"'psychodynamics of work'. Organization, v. 24, n. 1, 2017, pp. 18-35.

EISENHARDT, K. M. Building theories from case study research. Academy of management review, v. 14, n. 4, 1989, pp. 532-550.

ERICKSON, J. R.; RITTER, C. Emotional labor, burnout and inauthentidty: does gender matter. Social Psychology Quarterly, v. 64, n. 2, 2001, pp. 146-163.

FINCH, J.; ZHANG, S.; GEIGER, S. Managing in conflict: how actors distribute conflict in an industrial network. Industrial Marketing Management, v. 42, n. 7, 2013, pp. 1063-1073.

FINEMAN, S. A emoção e o processo de organizar. Handbook de estudos organizacionais, v. 2, 2001, pp. 157-189.

FLICK, U. Qualidade na pesquisa qualitativa: coleção pesquisa qualitativa. Porto Alegre: Bookman, 2009.

GONZÁLEZ REY, F. L. Sujeito e subjetividade: uma aproximação histórico-cultural. São Paulo: Pioneira Thomson Learning, 2003.

GOOTY, J. et al. Leadership, affect and emotions: a state of the science review. The Leadership Quarterly, v. 21, n. 6, 2010, pp. 979-1004.

HERNÁNDEZ, A. B.; FIERROS, D. E. M. La familia, grupo social permanente en las organizaciones desde una perspectiva psicoanalítica [The family, permanent social group in organizations from a psychoanalytic perspective]. Acción Psicológica, v. 16, n. 2, 2019, pp. 91-102.

HOCHSCHILD, A. R. Ideology and emotion management: a perspective and path for future research. Research agendas in the sociology of emotions, v. 117, 1990, pp. 117-142.

HOON, C. Meta-synthesis of qualitative case studies: an approach to theory building. Organizational Research Methods, v. 16, n. 4, 2013, pp. 522-556.

JOST, R. C. F.; BULGACOV, Y. L. M.; CAMARGO, D. Dimensão ideológica da emoção na gestão de vendedoras de cosméticos em uma empresa multinacional. Cadernos EBAPE. BR, v. 16, n. 2, 2018, pp. 232-249.

JUSTEN, G. S. et al. Inovação social e desenvolvimento local: uma análise de metassíntese. Revista de Gestão Social e Ambiental-RGSA, v. 14, n. 1, 2020, pp. 56-73.

KOK, A. M.; BAKKER, F. G. A.; GROENEWEGEN, P. Sustainability struggles: conflicting cultures and incompatible logics. Business \& Society, v. 58, n. 8, 2019, pp. 1496-1532.

LIVELY, K. J.; WEED, E. A. Emotion management: sociological insight into what, how, why, and to what end? Emotion Review, v. 6, n. 3, 2014, pp. 202-207.

MÖNKKÖNEN, K.; PUUSA, A. From disunited to joint action: dialogue reflecting the construction of organizational identity after a merger. SAGE Open, v. 5, n. 3, 2015, p. 2158244015599429.

PLATE, M. Shame and the undoing of leadership - An analysis of shame in organizations. New ways of studying emotions in organizations. Emerald Group Publishing Limited, 2015. 
POLLACK, J. M. et al. Passion at work: a meta-analysis of individual work outcomes. Journal of Organizational Behavior, v. 41, n. 4, 2020, pp. 311-331.

SEEFELD, R.; CENI, J. C. Qual é o lugar das narrativas na mudança organizacional? Uma metassíntese de estudos de casos qualitativos. Revista Gestão \& Conexões. Vitória, v. 8, n. 2, maio/ago. 2020, pp. 94-119.

STOWELL, A. F.; WARREN, S. The institutionalization of suffering: embodied inhabitation and the maintenance of health and safety in e-waste recycling. Organization Studies, v. 39, n. 5-6, 2018, pp. 785-809.

THIOLLENT, M. Estudos organizacionais: possível quadro referencial e interfaces. Revista Brasileira de Estudos Organizacionais, v. 1, n. 1, 2014, pp. 1-14.

VAN HULST, M.; YBEMA, S. From what to where: a setting-sensitive approach to organizational storytelling. Organization studies, v. 41, n. 3, 2020, pp. 365-391.

VIEIRA, A. M.; RIVERA, D. P. B. A Hermenêutica no Campo Organizacional: duas possibilidades interpretativistas de pesquisa. Revista Brasileira de Gestão de Negócios, v. 14, n. 44, p. 261-273, 2012.

VORONOV, M.; VINCE, R. Integrating emotions into the analysis of institutional work. Academy of Management review, v. 37, n. 1, p. 58-81, 2012.

WARING, S. Using live disaster exercises to study large multiteam systems in extreme environments: Methodological and measurement fit. Organizational Psychology Review, v. 9, n. 4, 2019, pp. 219-244.

YIN, R. K. Estudo de caso: planejamento e métodos. Porto Alegre: Bookman, 2015.

Recebido em: 8-2-2021

Aprovado em: 29-7-2021

Avaliado pelo sistema double blind review.

Disponível em http://mjs.metodista.br/index.php/roc 